Article

\title{
Chemical Composition, Antioxidant, and Antibacterial Activity of Wood Vinegar from Litchi chinensis
}

\author{
Jyh-Ferng Yang ${ }^{1}$, Cheng-Hong Yang ${ }^{2}$, Ming-Tsai Liang ${ }^{1}$, Zi-Jie Gao ${ }^{1}$, Yuh-Wern Wu ${ }^{1, *}$ \\ and Li-Yeh Chuang ${ }^{1, *}$ \\ 1 Department of Chemical Engineering and Institute of Biotechnology and Chemical Engineering, \\ I-Shou University, Kaohsiung 840, Taiwan; jfyang@isu.edu.tw (J.-F.Y.); mtliang@isu.edu.tw (M.-T.L.); \\ isu10237005M@cloud.isu.edu.tw (Z.-J.G.) \\ 2 Department of Electronic Engineering, National Kaohsiung University of Applied Sciences, \\ Kaohsiung 807, Taiwan; chyang@cc.kuas.edu.tw \\ * Correspondence: ywwu@isu.edu.tw (Y.-W.W.); chuang@isu.edu.tw (L.-Y.C.); \\ Tel.: +886-07-657-7711 (L.-Y.C.); Fax: +886-07-657-8945 (L.-Y.C.)
}

Academic Editor: Thomas Efferth

Received: 12 July 2016; Accepted: 24 August 2016; Published: 30 August 2016

\begin{abstract}
The antioxidant and antibacterial activities of wood vinegar from Litchi chinensis, and its components have been studied. The chemical compositions of wood vinegar were analyzed by gas chromatography-mass spectrometry (GC-MS). A total of 17 chemical compounds were identified, representing $83.96 \%$ of the compositions in the wood vinegar. Three major components, included 2,6-dimethoxyphenol (syringol, 29.54\%), 2-methoxyphenol (guaiacol, 12.36\%), and 3,5-dimethoxy4-hydroxytoluene $(11.07 \%)$, were found in the wood vinegar. Antioxidant activities of the acids were investigated from the aspects of 1,1-Diphyl-2-picrylhydrazyl (DPPH) free radicals scavenging capacity, superoxide anion radical scavenging capacity, and reducing power. The pyroligneous acid exhibited high antioxidant activity which was comparable to the reference standards (vitamin $\mathrm{C}$ and butylated hydroxyl toluene) at the same dose with $\mathrm{IC}_{50}$ values of $36.5 \mathrm{ppm}$ calculated by the DPPH radical scavenging assay, $38.38 \mathrm{~g}$ Trolox equivalent/100 $\mathrm{g}$ DW by the trolox equivalent antioxidant capacity (TEAC) assay, and 67.9 by the reducing power analysis. Antibacterial activity was evaluated using the disc diffusion and microdilution methods against a group of clinically antibiotic resistant isolates. The major components exhibited broad spectrum inhibition against all the bacterial strains with a range of disc inhibition zoon between 15-19 $\mathrm{mm}$. The minimum inhibition concentration and minimum bactericide concentration against the test strains was ranging in $0.95-3.80 \mu \mathrm{L} / 100 \mu \mathrm{L}$ and 1.90-3.80 $\mu \mathrm{L} / 100 \mu \mathrm{L}$, respectively. Most of the antibiotic resistant strains were more susceptible to the wood vinegar than the non-antibiotic resistant strain except the strain of ornithine resistant Staphylococcus aureus. Based on the chemical profile, it was considered that the strongest antioxidant and antibacterial activity of Litchi chinensis wood vinegar was due to its highly phenolic compositions. This study revealed that the Litchi chinensis wood vinegar is valuable to develop as alternative food antioxidant and antibiotics.
\end{abstract}

Keywords: Litchi chinensis wood vinegar; gas chromatography-mass spectrometry; antibacterial activity; antioxidant activity

\section{Introduction}

Wood vinegar, also called pyroligneous acid, is a brown, flavorful liquid produced by distillation of wood in the absence of air condition. When the gas generated from combustion is cooled, it condenses into liquid. The carbonization of many different types of wood can be used to produce various wood 
vinegars including Eucalyptus [1,2], oak [3], bamboo [4], mangrove [5,6], coconut shell [7], and apple trees. Many different sources of wood vinegar have been recognized as safe, natural inhibitors with various bioactivities, which make them suitable for use in antifungal, termiticidal, and repellent applications [8-12]. In addition, wood vinegar exhibits a high degree of antimicrobial activity against various microorganisms [12,13], along with significant antioxidant activity [14,15].

Lignin is known as a class of complex organic polymers that form important structural materials in the formation of cell walls, especially in wood and bark. Lignin makes it possible for the plant's vascular tissue to conduct water efficiently [16]. Pyrolysis of lignin during the combustion of wood or charcoal are able to provide a range of products, in which the most characteristic ones are methoxy-substituted phenols, such as guaiacol and syringol and their derivatives. In our daily life, these two chemicals provide the main flavor of smoked foods [17].

Gas chromatography mass spectroscopy (GC-MS), a sensitive hyphenated system, is widely used to analyze, identify, and quantify the chemical compositions of natural products. The unknown chemical composition of wood vinegar from different plants can be determined by matching of the peak mass spectra distribution with the NIST MS database [18].

Litchi chinensis is a popular fruit produced in bulk in Southern Taiwan. To improve tree development and productivity in the following years, Litchi trees must be pruned following each harvest, but most of the trimmings are discarded or burnt as fuel. However, these trimmings could be used to manufacture charcoal, producing wood vinegar as a byproduct. If the resulting wood vinegar possesses active biological properties, it would greatly increase the value of the Litchi cultivation.

Although previous studies have indicated that pyroligneous acid has potential as a natural antioxidant and antimicrobial agent, many studies have also reported that wood vinegar produced using different source materials might present different levels of bioactivity and different quantities of bioactive constituents. This study investigates the antioxidant and antibacterial activities of the wood vinegar from Litchi chinensis, and determines the chemical composition of the acid, using GC-MS to probe the relationship between the bioactivity and the constituents.

\section{Results and Discussion}

\subsection{Chemical Profiles of Wood Vinegar From GC-MS}

The GC-MS analysis of various chemical compositions from the wood vinegar was performed using an Agilent HP-5ms Ultra Inert capillary column (Agilent Technologies, NEW Castle, DE, USA) and total ion chromatogram (TIC) (Agilent Technologies). The absorbance peaks of the chemical compositions from the wood vinegar are shown in Figure 1. The constituents were identified by comparing their mass spectra against the database of NIST MS 14.0 with matches of greater than or equal to $90 \%$. The GC-MS analysis of the wood vinegar revealed a total of 17 different components as listed in Table 1 , representing $83.96 \%$ of all compositions in the wood vinegar. Among the 17 different compounds, three major components (Figure 2) were 2,6-dimethoxyphenol (syringol, 29.54\%), 2-methoxyphenol (guaiacol, 12.36\%), and 3,5-dimethoxy-4-hydroxytoluene (11.07\%). The minor components were 3-methoxy-1,2-benzenediol (6.12\%), catechol $(5.17 \%)$, creosol $(3.15 \%)$, 4-ethyl-2-methoxyphenol (3.09\%), 3-methyl-1,2-cyclopentanedione $(2.65 \%)$, and phenol $(2.03 \%)$. Other components constituted less than $2 \%$ of the total yield.

As shown in Table 1, the GC-MS analysis revealed a total of 17 chemical constituents of wood vinegar, most of which were phenol compounds.

Lignin is a stable biopolymer assembled from hydroxyphenylpropane (C6-C3) units such as sinapyl alcohol, coniferyl alcohol and 4-hydroxycinnamyl alcohol (Figure 3) [8]. Therefore, phenolic compounds can be obtained from the cleavage of ether and carbon-carbon bonds of lignin. 


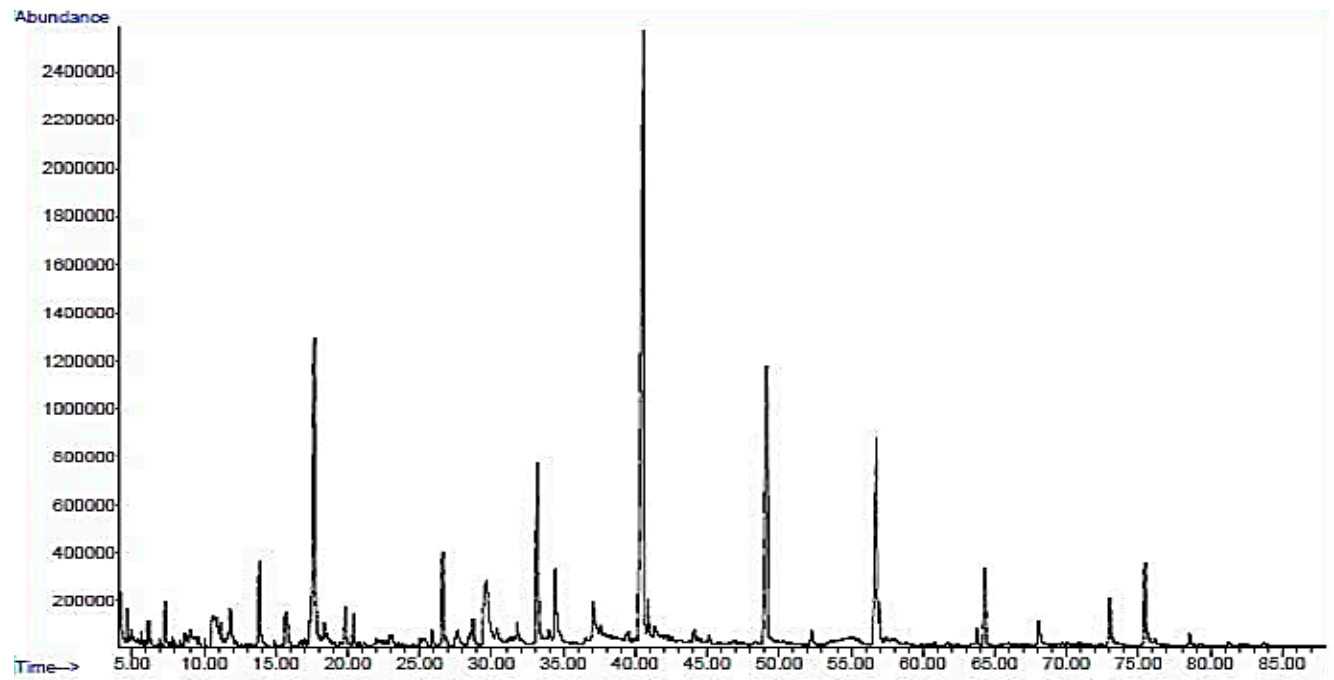

Figure 1. GC-MS analysis of the chemical constituents of the wood vinegar.<smiles>COc1cccc(OC)c1O</smiles>

2,6-Dimethoxyphenol<smiles>COc1ccccc1O</smiles>

2-methoxyphenol<smiles>COc1cc(C)cc(OC)c1O</smiles>

3,5-Dimethoxy-4-hydroxytoluenel

Figure 2. Three major components of the wood vinegar.

Table 1. Chemical constituents of the wood vinegar analyzed by GC-MS.

\begin{tabular}{cccccc}
\hline No. & $\begin{array}{c}\text { RT } \\
(\text { min })\end{array}$ & Name of the Compounds & $\begin{array}{c}\text { Molecular } \\
\text { Formula }\end{array}$ & $\begin{array}{c}\text { Molecular } \\
\text { Weight }\end{array}$ & $\begin{array}{c}\text { \% } \\
\text { Area }\end{array}$ \\
\hline 1 & 4.644 & 2-methyl-pyridine & $\mathrm{C}_{6} \mathrm{H}_{7} \mathrm{~N}$ & 93.06 & 0.23 \\
2 & 10.664 & Phenol & $\mathrm{C}_{6} \mathrm{H}_{6} \mathrm{O}$ & 94.04 & 2.03 \\
3 & 13.869 & 3-methyl-1,2-cyclopentanedione & $\mathrm{C}_{6} \mathrm{H}_{8} \mathrm{O}_{2}$ & 112.05 & 2.65 \\
4 & 15.682 & 2-methylphenol & $\mathrm{C}_{7} \mathrm{H}_{8} \mathrm{O}$ & 108.06 & 1.54 \\
5 & 17.663 & 2-methoxyphenol (Guaiacol) & $\mathrm{C}_{7} \mathrm{H}_{8} \mathrm{O}_{2}$ & 124.05 & 12.36 \\
6 & 19.838 & Maltol & $\mathrm{C}_{6} \mathrm{H}_{6} \mathrm{O}_{3}$ & 126.03 & 1.02 \\
7 & 20.416 & 3-ethyl-2-hydroxy-2-cyclopenten-1-one & $\mathrm{C}_{7} \mathrm{H}_{10} \mathrm{O}_{2}$ & 126.07 & 0.74 \\
8 & 26.601 & Creosol & $\mathrm{C}_{8} \mathrm{H}_{10} \mathrm{O}_{2}$ & 138.07 & 3.15 \\
9 & 29.641 & Catechol & $\mathrm{C}_{6} \mathrm{H}_{6} \mathrm{O}_{2}$ & 110.04 & 5.17 \\
10 & 33.199 & $\mathrm{C}_{7} \mathrm{H}_{8} \mathrm{O}_{3}$ & 140.05 & 6.12 \\
11 & 34.415 & 3-methoxy-1,2-benzenediol & $\mathrm{C}_{9} \mathrm{H}_{12} \mathrm{O}_{2}$ & 152.08 & 3.09 \\
12 & 37.068 & 4-ethyl-2-methoxyphenol & $\mathrm{C}_{7} \mathrm{H}_{8} \mathrm{O}_{2}$ & 124.05 & 1.66 \\
13 & 40.568 & 4-methyl-1,2-benzenediol & $\mathrm{C}_{8} \mathrm{H}_{10} \mathrm{O}_{3}$ & 154.06 & 29.54 \\
14 & 40.895 & 2,6-dimethoxyphenol (Syringol) & $\mathrm{C}_{8} \mathrm{H}_{10} \mathrm{O}_{3}$ & 154.06 & 0.93 \\
15 & 49.159 & 3,4-dimethoxyphenol & $\mathrm{C}_{9} \mathrm{H}_{12} \mathrm{O}_{3}$ & 168.08 & 11.07 \\
16 & 56.966 & 1-(4-hydroxy-3-methoxyphenyl)-2-propanone & $\mathrm{C}_{10} \mathrm{H}_{12} \mathrm{O}_{3}$ & 180.08 & 1.10 \\
17 & 73.001 & 1-(4-hydroxy-3,5-dimethoxyphenyl)-ethanone & $\mathrm{C}_{10} \mathrm{H}_{12} \mathrm{O}_{4}$ & 196.07 & 1.59 \\
\hline
\end{tabular}


<smiles>COc1cc(/C=C/CO)cc(OC)c1O</smiles>

sinapyl alcohol<smiles>COc1cc(/C=C/CO)ccc1O</smiles>

coniferyl alcohol<smiles>OC/C=C/c1ccc(O)cc1</smiles>

4-hydroxycinnamyl alcohol

Figure 3. Molecular structures of lignin units.

The phenol compounds identified from the wood vinegar could be classified as syringol-type $(42.2 \%$, Figure 4a), including 2,6-dimethoxyphenol (29.54\%), 3,5-dimethoxy-4-hydroxytoluene (11.07\%), and 1-(4-hydroxy-3,5-dimethoxyphenyl)-ethanone (1.59\%), guaiacol-type (16.55\%, Figure $4 \mathrm{~b})$, including 2-methoxyphenol (12.36\%), 4-ethyl-2-methoxyphenol (3.09\%), and 1-(4-hydroxy-3-methoxyphenyl)-2propanone $(1.10 \%)$, and benzenediol-type (12.59\%, Figure $4 \mathrm{c})$, including catechol (5.17\%), 3-methoxy1,2-benzenediol (6.12\%), and 4-methyl-1,2,-benzenediol (1.66\%).<smiles>COc1cccc(OC)c1O</smiles>

2,6-Dimethoxyphenol<smiles>COc1cc(C)cc(OC)c1O</smiles>

3,5-Dimethoxy-4-hydroxytoluenel<smiles>COc1cc(C(C)=O)cc(OC)c1O</smiles>

1-(4-hydroxy-3,5-dimethoxyphenyl)ethanone

(a)<smiles>COc1ccccc1O</smiles>

2-methoxyphenol<smiles>Oc1ccccc1O</smiles>

Catechol<smiles>CCc1ccc(O)c(OC)c1</smiles>

4-Ethyl-2-methoxyphenol

(b)<smiles>COc1cccc(O)c1O</smiles>

3-Methoxy-1,2-benzenediol<smiles>COc1cc(CC(C)=O)cc(OC)c1O</smiles>
propanone

(c)

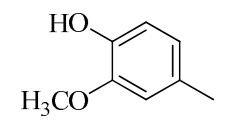

4-Methyl-1,2-benzenediol

Figure 4. Molecular structures of the phenol compounds from the wood vinegar (a) syringol-type; (b) guaiacol-type; and (c) benzenediol-type.

Among the phenolic components, catechol is probably produced via the demethylation of guaiacol and 3-methoxy-1,2-benzenediol can be obtained from the demethylation of syringol [15]. The results shown in Table 1 indicate that the major lignin units of the wood vinegar were sinapyl alcohol and coniferyl alcohol.

\subsection{Antibacterial Ability}

The results for the in vitro antibacterial properties of the wood vinegar are presented in Table 2. According to the disc inhibition assay, all of the test pathogens were sensitive to the wood vinegar with a range of disc inhibition zone (DIZ) between 15 to $19 \mathrm{~mm}$, indicating that the wood vinegar possesses a broad antibacterial spectrum against different pathogens, with a maximum DIZ (19 mm) against the clinical isolate of Staphylococcus aureus, followed by Acinetobacter baumannii, Pseudomonas aeruginosa and Ornithine resistant Staphylococcus aureus with slightly smaller DIZ values (16-17 mm). 
Table 2. Antibacterial activity of the wood vinegar.

\begin{tabular}{|c|c|c|c|c|}
\hline \multirow{2}{*}{ Strains * } & \multicolumn{2}{|c|}{ Disc Inhibition Zone (mm) } & \multirow{2}{*}{$\begin{array}{c}\text { MIC } \\
(\mu \mathrm{L} / 100 \mu \mathrm{L})\end{array}$} & \multirow{2}{*}{$\begin{array}{c}\text { MBC } \\
(\mu \mathrm{L} / 100 \mu \mathrm{L})\end{array}$} \\
\hline & Wood Vinegar & Tetracycline $(7.5 \mathrm{mg} / \mathrm{mL})$ & & \\
\hline Ec 25257 & $15.20 \pm 0.40$ & $27.90 \pm 0.00$ & $2.38-2.86$ & 2.86 \\
\hline $\mathrm{Ab} 814$ & $17.50 \pm 0.20$ & $12.73 \pm 0.53$ & 1.90 & 2.38 \\
\hline Sa 985 & $19.00 \pm 1.00$ & $17.09 \pm 0.09$ & $0.95-1.90$ & 1.90 \\
\hline Pa 717 & $17.70 \pm 0.20$ & $23.34 \pm 1.91$ & $0.95-1.90$ & 1.90 \\
\hline ORSa 220 & $16.30 \pm 1.10$ & $21.31 \pm 0.11$ & $2.38-3.80$ & 3.80 \\
\hline
\end{tabular}

* Ec: Escherichia coli; Ab: Acinetobacter baumannii; Sa: Staphylococcus aureus; Pa: Pseudomonas aeruginosa; ORSa: Ornithine-resistant Staphylococcus aureus ${ }^{\#}$ : mean \pm SD.

The results of minimum inhibitory concentration (MIC) and minimum bactericidal concentration (MBC) determinations showed that the wood vinegar exhibits significant antibacterial activity against Staphylococcus aureus and Pseudomonas aeruginosa, with respective MIC and MBC values of 0.95-1.90 $\mu \mathrm{L} / 100 \mu \mathrm{L}$ and $1.90 \mu \mathrm{L} / 100 \mu \mathrm{L}$. With the exception of ornithine-resistant Staphylococcus aureus (ORSa), most of the tested antibiotic-resistant strains showed moderate antibacterial activity against the standard strain (ATCC 25257), a non-antibiotic resistant strain, with respective MIC and MBC values of $2.38-2.86 \mu \mathrm{L} / 100 \mu \mathrm{L}$ and $2.86 \mu \mathrm{L} / 100 \mu \mathrm{L}$.

Chan recently reported that Matang wood vinegar displayed potent antibacterial activity [18] against the strains of Gram-positive Bacillus cereus, Micrococcus luteus and Staphylococcus aureus, and Gram-negative Escherichia coli, Salmonella typhi, and Pseudomonas aeruginosa. Based on their MIC determination results, the overall ranking of susceptibility was B. cereus $>$ M. luteus $\sim$ S. aureus $\sim$ P. aeruginosa $>$ E. coli $\sim$ S. typhi. Their results are consistent to our finding that the Gram-positive strain S. aureus was the most susceptible, while the Gram-negative E. coli showed only light susceptibility to the wood vinegar. Many previous reports suggest that Gram-positive bacteria are generally more susceptible to plant extracts than Gram-negative bacteria because of the absence of an outer membrane of lipoprotein and lipopolysaccharide. An outer membrane of lipoprotein and lipopolysaccharide is selectively permeable and can regulate access of antimicrobials into the underlying cell structures [19]. However, the Gram-positive strain ORSA showed the lowest susceptible to the wood vinegar, and it is presumed that strong biofilm formers (ORSA) might result in stronger drug resistance [20]. Other wood vinegar sources including bamboo, eucalyptus, and rubber also exhibited antimicrobial activity against dermatitis, environment, and plant bacteria, as well as fungi [21]. A concentration of less than $10 \%$ is suggested as suitable for use as an antimicrobial agent while preventing leaf burning and some pathogenic fungi on PDA.

More than 200 chemical constituents of pyroligneous acid have been identified from different resources [1-9]. Earlier reports showed that the major components of organic acids and phenolics in wood vinegar can inhibit pathogenic fungi and bacteria [10-13]. The chemical profile presented in Table 1 shows that more than $70 \%$ of all wood vinegar compositions were identified as phenolic compounds, of which three major components exhibit antibacterial activity: 2,6-dimethoxyphenol (Syringol, 29.54\%), 2-methoxyphenol (guaiacol, 12.36\%), and 3,5-dimethoxy-4-hydroxytoluene (11.07\%). Therefore, we conclude that the three major phenolics and other minor organic acids contribute to the antibacterial activities of the wood vinegar from Litchi chinensis.

\subsection{Antioxidant Assay}

The antioxidant assay results are shown in Table 3. In the DPPH radical scavenging ability assay, the DPPH $\mathrm{IC}_{50}$ value (the concentration required to scavenge DPPH radical by $50 \%$ ) of wood vinegar was about $36.53 \mathrm{ppm}$ (Table 3). The DPPH IC I0 $_{5}$ values of butylated hydroxyl toluene (BHT) and vitamin $C$ were about $175 \mathrm{ppm}$ and $7 \mathrm{ppm}$, respectively. The result indicates that the radical scavenging ability of wood vinegar is higher than the commercial chemical antioxidant (BHT), but lower than the natural antioxidant (vitamin $\mathrm{C}$ ). The reducing power analysis found that the reducing 
power increased with the concentration of each sample. The ranking order for reducing power was wood vinegar $\left(67.9 \mathrm{abs} / 10^{-3} \mathrm{ppm}\right)>\operatorname{Vitamin} \mathrm{C}\left(7.3 \mathrm{abs} / 10^{-3} \mathrm{ppm}\right)>$ BHT $\left(2.2 \mathrm{abs} / 10^{-3} \mathrm{ppm}\right)$. Significantly, the wood vinegar exhibited higher reducing power than the commercial antioxidants (BHT and vitamin C). For the Trolox equivalent antioxidant capacity (TEAC) assay, the wood vinegar (38.38 g Trolox/100 g DW) and Vitamin C (38.47 g Trolox/100 g DW) showed similar TEAC values that were both higher than that of BHT (35.64 $\mathrm{g}$ Trolox/100 $\mathrm{g}$ DW). The TEAC assay results indicate that wood vinegar possesses antioxidant ability similar to that of vitamin $C$ and higher antioxidant capacity than BHT. The total phenolic and flavonoid contents in the wood vinegar were respectively $37.34 \mathrm{~g}$ gallic acid/100 g DW and $4.42 \mathrm{~g}$ quercetin/100 $\mathrm{g}$ DW (Table 3). These results imply that the wood vinegar contains a high quantity of phenolic compounds and flavonoids, which is consistent with the results obtained from GC-MS analysis.

Table 3. Antioxidant activity of the wood vinegar".

\begin{tabular}{|c|c|c|c|c|c|}
\hline Samples & $\begin{array}{l}\mathrm{DPPH} \mathrm{IC}_{50} \\
\text { (ppm) }\end{array}$ & $\begin{array}{c}\text { TPC (g Gallic acid/ } \\
100 \mathrm{~g} \mathrm{DW})\end{array}$ & $\begin{array}{c}\text { TFC (g Quercetin/ } \\
100 \mathrm{~g} \mathrm{DW})\end{array}$ & $\begin{array}{c}\text { TEAC (g Trolox } \\
\text { Equivalent/ } \\
100 \mathrm{~g} \mathrm{DW})\end{array}$ & $\begin{array}{l}\text { Reducing Power } \\
\text { (abs } / 10^{-3} \text { ppm) }\end{array}$ \\
\hline Wood vinegar & $36.53 \pm 1.57$ & $37.34 \pm 0.07$ & $4.42 \pm 0.01$ & $38.38 \pm 0.12$ & 67.9 \\
\hline BHT & $175.12 \pm 19.92$ & - & - & $35.64 \pm 0.35$ & 2.2 \\
\hline Vitamin C & $7.01 \pm 0.61$ & - & - & $38.47 \pm 0.04$ & 7.3 \\
\hline
\end{tabular}

BHT: butylated hydroxyl toluene; DPPH: DPPH free radical scavenging ability; TPC: total phenolic content; TFC: total flavonoid content; TEAC: trolox equivalent antioxidant capacity; -: undetected ${ }^{\#}:$ mean \pm SD.

Previous studies have shown that phenolic compounds exhibit strong free radical scavenging capability, reducing power, and antioxidant capability and can, therefore, be used as reductants and antioxidants. Plant phenolic and flavonoid components are widely distributed in the tissues of plants, and also play a pivotal role in highly effective bioactivity. Due to the side effects of chemical synthetic antioxidants (such as BHT and BHA), more attention is now focused on the antioxidant activity of phenolic compounds from plants. Previous reports have verified that the pyroligneous acid exhibits significant antioxidant activity. Ma et al. [22] found that the fruit of $S$. chinensis exhibits superoxide anion scavenging activity and antioxidant activity. Loo et al. $[5,6]$ demonstrated that pyroligneous acid from the mangrove plant and Rhizophora apiculate exhibit antioxidant and free radical scavenging activities. All these results indicate that pyroligneous acid could potentially be a natural antioxidant.

Many studies have indicated that pyroligneous acid is rich in phenolic compounds [10-12], which are pyrolytic products of lignin and hemicellulose, comprising $30 \%-60 \%$ of the total organic compounds in the acid. 2,6-dimethoxyphenol, also known as syringol, has been identified as having a woody/herby flavor and smoky odor [23]. Syringol exhibited antioxidant activities based on its DPPH radical scavenging activity, ABTS radical cation scavenging activity, phosphomolybdenum and ferric reducing antioxidant power [6]. In addition, 3-Methyl-1,2-cyclopentanedione may be regarded as a potent regulator of (ONOO-)-mediated diseases via direct scavenging of the reactivity of and ONOOcan prevent (ONOO-)-induced damage of GSH reductase [24]. Loo et al. reported the isolation of three antioxidative compounds (syringol, catechol, and 3-methoxycatechol) from mangrove wood vinegar [5] which is consistent to our finding in the Lichi wood vinegar. All of these results indicate that the pyroligneous acid from Lichi has potential to be developed as a natural antioxidant.

\section{Materials and Methods}

\subsection{Materials and Chemicals}

The raw wood vinegar was prepared from Litchi chinensis using a traditional Japanese black charcoal kiln and collected by using running water through a shuttle (7-10 in length), which connected with the chimneys, to condense the smoke. Pyroligneous acids were collected from a temperature range of $100-600{ }^{\circ} \mathrm{C}$ and prepared by the Bu-Quang charcoal company (Kaohsiung, Taiwan). The raw wood vinegar was stored in the dark at $4{ }^{\circ} \mathrm{C}$ for analysis. All chemicals (1,1-diphyl-2-picrylhydrazyl (DPPH), 
butylated hydroxytoluene (BHT), trichloroacetic acid (TAC), ascorbic acid, Folin Ciocalteu's reagent, potassium ferricyanide, ferric chloride, sodium carbonate, and all analytical chemicals) were purchased from Sigma (Sternheim, Germany). The clinical antibiotic resistant strains (Staphylococcus aureus 985, Acinetobacter baumannii 814, Pseudomonas aeruginosa 717, and ornithine-resistant Staphylococcus aureus 220) used in this research were isolated from blood and phlegm samples provided by Chia-Yi Christian Hospital (Chia-Yi, Taiwan). The standard strain (Escherichia coli ATCC 25257) was purchased from the Taiwan's Food Industry Research and Development Institute Bioresources Collection and Research Center (Hsinchu, Taiwan).

\subsection{Instrument}

Analysis used an Agilent 7890B gas chromatography instrument, combined with an Agilent-5977A mass spectrometer (Agilent Technologies) equipped with electron ionization (EI) and quadrupole analyzer, and an Agilent Chem Station data system. GC separation was performed on a $30 \mathrm{~m} \mathrm{HP-5ms}$ Ultra Inert capillary column with an internal diameter of $0.25 \mathrm{~mm}$ and a film thickness of $0.25 \mu \mathrm{m}$ (Agilent 19091S-433UI, Agilent Technologies).

\subsection{Methods}

\subsubsection{Phytochemical Composition Analysis}

The components of wood vinegar were subjected to GC-MS analysis on an Agilent system consisting of a model 7890B gas chromatographer and a model 5977A mass selective detector (MSD, electron energy, $70 \mathrm{eV}$ ). The carrier gas was helium $(99.99 \%)$ with a flow rate of $0.8 \mathrm{~mL} / \mathrm{min}$. The injector and detector temperatures were respectively set at $250^{\circ} \mathrm{C}$ and $250^{\circ} \mathrm{C}$. Spectra were obtained over a scan range of 50 to $550 \mathrm{amu}$ at 2 scans/s. The GC program was set as follows: the initial temperature was $60^{\circ} \mathrm{C}$ and held for $10 \mathrm{~min}$, then increased by $2{ }^{\circ} \mathrm{C} / \mathrm{min}$ to $80^{\circ} \mathrm{C}$ and held for $5 \mathrm{~min}$, then raised by $2{ }^{\circ} \mathrm{C} / \mathrm{min}$ to $110^{\circ} \mathrm{C}$ and held $6 \mathrm{~min}$, then raised by $2{ }^{\circ} \mathrm{C} / \mathrm{min}$ to $120^{\circ} \mathrm{C}$ and held for $5 \mathrm{~min}$, and finally raised by $2{ }^{\circ} \mathrm{C} / \mathrm{min}$ to $180{ }^{\circ} \mathrm{C}$ and held at $180^{\circ} \mathrm{C}$ for $2 \mathrm{~min}$. The wood vinegar $(1.0 \mu \mathrm{L})$ was injected automatically while maintaining a solvent delay of $4 \mathrm{~min}$. Interpretation of the mass spectrum was made by comparing the peak distribution against the database of National Institute Standard and Technology (NIST MS 14.0, Gaithersburg, MD, USA). Relative percentages of the chemical compositions were calculated based on the GC peak areas without correction.

\subsubsection{Antibacterial Activity Assay}

Disc Inhibitory Assay

A Petri dish was prepared with a base layer of Muller Hinton (MH) agar $(10 \mathrm{~mL})$ and a top layer of $0.75 \% \mathrm{MH}$ agar $(5 \mathrm{~mL})$, then inoculated with $50 \mu \mathrm{L}$ of each bacterial suspension $\left(10^{5} \mathrm{CFU} / \mathrm{mL}\right)$. Paper discs (6 mm in diameter) were impregnated with $30 \mu \mathrm{L}$ of wood vinegar and placed on the inoculated plates, then incubated at $37^{\circ} \mathrm{C}$ for $14 \mathrm{~h}$. The diameters of the inhibition zones (DIZ) were measured [25].

Determination of Minimum Inhibitory Concentration (MIC) and Minimum Bactericidal Concentration (MBC)

A broth dilution method was used to determine the minimum inhibitory concentration (MIC) and minimum bactericidal concentration (MBC) [25]. The wood vinegars (50, 100, 125, 150, and $200 \mu \mathrm{L}$ ) were diluted in $5 \mathrm{~mL}$ LB broth. Each strain $\left(10^{6} \mathrm{CFU} / \mathrm{mL}\right)$ was added and incubated at $37^{\circ} \mathrm{C}$ at $220 \mathrm{rpm}$ for $16 \mathrm{~h}$. Subsequently, $100 \mu \mathrm{L}$ of the culture mixture was coated on the MH agar medium, and the colony numbers were counted after incubating for $16 \mathrm{hrs}$ at $37^{\circ} \mathrm{C}$. The MIC is defined as the concentration level that can inhibit $90 \%$ of bacteria development, with $99 \%$ bacterial inhibition set as the MBC. 


\subsubsection{Determination of Total Phenolic Content}

The total phenolic content of wood vinegar was determined using the Folin-Ciocalteu method using gallic acid as a standard [26]. Briefly, $0.1 \mathrm{~mL}$ of wood vinegar was added into $0.1 \mathrm{~mL}$ of $25 \%$ Folin-Ciocalteu reagent and $2 \mathrm{~mL}$ of $2 \% \mathrm{Na}_{2} \mathrm{CO}_{3}$ solution with thorough shaking. After reacting at room temperature for $30 \mathrm{~min}$, the absorbance was measured at $760 \mathrm{~nm}$ and the phenolic content was calculated according to the equation that was obtained from the standard gallic acid.

\subsubsection{Determination of Flavonoids Content}

The total flavonoid content of wood vinegar was determined using the method described as our previous study [26] with slight modifications. Briefly, one $\mathrm{mL}$ of the solution containing $1 \mathrm{mg} / \mathrm{mL}$ wood vinegar with methanol was added into $0.1 \mathrm{~mL}$ of $10 \%$ aluminium nitrate, $0.1 \mathrm{~mL}$ of $1 \mathrm{M}$ potassium acetate and $3.8 \mathrm{~mL}$ of methanol. After reacting at room temperature for $40 \mathrm{~min}$, the absorbance was read spectrophotometrically at $415 \mathrm{~nm}$, using quercetin as a standard. The concentrations of flavonoid compounds were calculated using the equation obtained from the standard quercetin graph.

\subsubsection{Antioxidant Activity Assay}

\section{DPPH Free Radical Scavenging Ability}

The DPPH free radical scavenging ability of wood vinegar was evaluated using the method described as our previous study [26] with some modifications. Briefly, one $\mathrm{mL}$ of various concentrations of wood vinegar in methanol was added to $0.25 \mathrm{~mL}$ of DPPH solution in methanol. The mixture was shaken and allowed to stand for $30 \mathrm{~min}$ in room temperature. The absorbance of the resulting solution was then measured at $517 \mathrm{~nm}$ with a spectrophotometer. The percentage of DPPH free radical inhibition was calculated with the following equation:

$$
\text { DPPH Inhibition }(\%)=\left(1-\frac{\text { Abs. of Exp. }- \text { Abs. of Comp. }}{\text { Abs. of control }}\right) \times 100 \%
$$

\section{Reducing Power}

The reducing power of wood vinegar was determined using the method described as our previous study [26] with some modifications. Briefly, $150 \mu \mathrm{L}$ of wood vinegar in methanol was mixed with $150 \mu \mathrm{L}$ of $200 \mathrm{mM}$ sodium phosphate buffer ( $\mathrm{pH}$ 6.6) and $150 \mu \mathrm{L}$ of $1 \% \mathrm{~K}_{3} \mathrm{Fe}(\mathrm{CN})_{6}$. The mixture was then incubated at $50{ }^{\circ} \mathrm{C}$ for $20 \mathrm{~min}$. Subsequently, $150 \mu \mathrm{L}$ of $10 \%$ trichloroacetic acid, $600 \mu \mathrm{L}$ of double deionized water, and $600 \mu \mathrm{L}$ of $\mathrm{FeCl}_{3}$ were added and the mixture was incubated for a further $14 \mathrm{~min}$. The absorbance of each reaction mixture was measured at $700 \mathrm{~nm}$. A higher absorbance indicates a higher reducing power.

\section{Trolox Equivalent Antioxidant Capacity}

The Trolox equivalent antioxidant capacity (TEAC) of wood vinegar was determined as our previous study [26] with some modifications. In brief, $20 \mu \mathrm{L}$ of various concentration of wood vinegar in methanol was mixed with $1 \mathrm{~mL}$ of $0.175 \mathrm{mM}$ ABTS solution, and the mixture was shaken and allowed to stand for $10 \mathrm{~min}$ at room temperature. The absorbance of the resulting solution was then measured at $734 \mathrm{~nm}$ with a spectrophotometer. Percentage of ABTS radical inhibition was calculated with the following equation:

$$
\text { Inhibition }(\%)=\left[1-\left(\frac{\text { Abs. of sample }}{\text { Abs. of control }}\right) \times 100 \%\right]
$$


The TEAC value was calculated with the following equation:

$$
\mathrm{TEAC}=\left(\frac{\mathrm{IC}_{50} \text { of trolox }}{\mathrm{IC}_{50} \text { of sample }}\right)
$$

\subsubsection{Statistical Analysis}

Data were expressed as mean and standard deviation (SD). A one way variance was used to analyze data, with $p<0.05$ representing a significant difference between means (Duncan's multiple range test).

\section{Conclusions}

This is the first study of the chemical composition, and antibacterial and antioxidant activities of wood vinegar from Litchi chinensis. The results reveal that Lichi wood vinegar contains seventeen compounds in various concentrations. More than $70 \%$ of the components were identified as phenolic compounds which could be classified into the syringol-type (42.2\%), guaiacol-type (16.55\%), and the benzenediol-type (12.59\%). Antioxidant activity assay results showed significant antioxidant activity comparable to commercial antioxidants. Moreover, the wood vinegar showed significant antibacterial activity against clinical antibiotic-resistant pathogens, which implies they can be developed into useful sterile products for medical, aquaculture, and livestock breeding applications. The results suggest the antioxidant and antibacterial activities of Litchi chinensis wood vinegar are contributed by the three major phenolic compounds, 2,6-dimethoxyphenol (Syringol, 29.54\%), 2-methoxyphenol (guaiacol, $12.36 \%)$, and 3,5-dimethoxy-4-hydroxytoluene (11.07\%). The chemical constituents of the wood vinegar must be identified to maximize utilization.

Acknowledgments: The work was partly supported by the Ministry of Science and Technology (nos. MOST 104-2221-E-214-035-MY2 and NSC 100-NU-E-214-002-NU) and I-Shou University (no. ISU104-02-01A).

Author Contributions: J.-F.Y. and C.-H.Y. conceived and designed the experiments; J.-F.Y. and Z.-J.G. performed the experiments; C.-H.Y., M.-T.L. and Y.-W.W. analyzed the data; M.-T.L. and L.-Y.C. contributed reagents/materials/analysis tools; J.-F.Y. and L.-Y.C. wrote the paper.

Conflicts of Interest: The authors declare no conflict of interest.

\section{References}

1. Amen-Chen, C.; Pakdel, H.; Roy, C. Separation of phenols from Eucalyptus wood tar. Biomass Bioenerg. 1977, 13, 25-37.

2. Pimenta, A.S.; Bayana, J.M.; Garcia, M.T.; Splanas, A.M. Evaluation of acute toxicity and genotoxicity of liquid products from pyrolysis of Eucalyptus grandis wood. Arch. Environ. Contam. Toxic. 2000, 38, 169-175.

3. Guillen, M.D.; Manzanos, M.J. Study of the volatile composition of an aqueous oak smoke preparation. Food Chem. 2002, 79, 283-292.

4. Mu, J.; Uehara, T.; Furuno, T. Effect of bamboo vinegar on regulation of germination and radicle growth of seed plants II: Composition of moso bamboo vinegar at different collection temperature and its effects. J. Wood Sci. 2004, 50, 470-476.

5. Loo, A.Y.; Jain, K.; Darah, I. Antioxidant and radical scavenging activities of the pyroligneous acid from a mangrove plant, Rhizophora apiculate. Food Chem. 2007, 104, 300-307.

6. Loo, A.Y.; Jain, K.; Darah, I. Antioxidant activity of compounds isolated from the pyroligneous acid, Rhizophora apiculate. Food Chem. 2008, 107, 1151-1160.

7. Wititsiri, S. Production of wood vinegars from coconut shells and additional materials for control of termite workers, Odontotermes sp. and striped mealy bugs, Ferrisia virgate. Songklanakarin J. Sci. Technol. 2011, 33, 349-354.

8. Amen-Chen, C.; Pakdel, H.; Roy, C. Production of monomeric phenols by thermochemical conversion of biomass: A review. Bioresour. Technol. 2001, 79, 277-299.

9. Oramahi, H.A.; Yoshimura, T. Antifungal and antitermitic activities of wood vinegar from Vitex pubescens Vahl. J. Wood Sci. 2013, 59, 344-350. 
10. Velmurugan, N.; Han, S.S.; Lee, Y.S. Antifungal activity of neutralized wood vinegar with water extracts of Pinus densiflora and Quercus serrata saw dusts. Int. J. Environ. Res. 2009, 3, 167-176.

11. Baimark, Y.; Niamsa, N. Study on wood vinegars for use as coagulating and antifungal agents on the production of natural rubber sheets. Biomass Bioenerg. 2009, 33, 994-998.

12. Ma, X.H.; Wei, Q.; Zhang, S.S.; Shi, L.; Zhao, Z. Isolation and bioactivities of organic acids and phenols from walnut shell pyroligneous acid. J. Anal. Appl. Pyrolysis 2011, 91, 338-343.

13. Hwang, Y.H.; Matsushita, Y.I.; Sugamoto, K.; Matsui, T. Antimicrobial effect of the wood vinegar from Cryptomeria japonica Sapwood on Plant Pathogenic Microorganisms. J. Microbiol. Biotechnol. 2005, 15, 1106-1109.

14. Ronald, H.A. Gas Chromatography Mass Spectroscopy. In Handbook of Instrumental Techniques for Analytical Chemistry; Prentice Hall PTR: Upper Saddle River, NJ, USA, 1997; pp. 609-611.

15. Van Bergen, P.F.; Poole, I.; Ogilvie, T.M.; Caple, C.; Evershed, R.P. Evidence for demethylation of syringyl moieties in archaeological wood using pyrolysis-gas chromatography/mass spectrometry. Rapid Commun. Mass Spectrom. 2000, 14, 71-79. [CrossRef]

16. Martone, P.T.; Estevez, J.M.; Lu, F.; Ruel, K.; Denny, M.W.; Somerville, C.; Ralph, J. Discovery of lignin in seaweed reveals convergent evolution of cell-wall architecture. Curr. Biol. 2009, 169-175. [CrossRef] [PubMed]

17. Wittkowski, R.; Ruther, J.; Drinda, H.; Rafiei-Taghanaki, F. Formation of smoke flavor compounds by thermal lignin degradation. ACS Symp Ser. 1992, 490, 232-243.

18. Chan, E.W.; Tan, Y.P.; Chin, S.J.; Gan, L.Y. Antioxidant and anti-tyrosinase properties of wood vinegar from Matang mangroves, Malaysia. ISME/G LOMIS Electron. J. 2012, 10, $19-21$.

19. Chan, E.W.; Fong, C.H.; Kang, K.X.; Chong, H.H.; Chong, H.H. Potent antibacterial activity of wood vinegar from Matang mangroves, Malaysia. SME/G LOMIS Electron. J. 2012, 10, 10-12.

20. Vijayakumar, S.; Rajenderan, I.; Laishram, I.; Anandan, I.; Balaji, I.; Biswas, I. Biofilm Formation and Motility Depend on the Nature of the Acinetobacter baumannii Clinical Isolates Front. Public Health 2016. [CrossRef]

21. Chalermsan, Y.; Peerapan, S. Wood vinegar: By-product from rural charcoal kiln and its role in plant protection. Asain J. Food Agro-Ind. 2009, S189-S195.

22. Ma, C.; Li, W.; Zu, Y.; Yang, L.; Li, J. Antioxidant Properties of Pyroligneous Acid Obtained by Thermochemical Conversion of Schisandra chinensis Baill. Molecules 2014, 19, 20821-20838. [CrossRef] [PubMed]

23. Zhu, R.H.; Xue, Q.C.; Li, Z.C. Handbook of Synthetic Flavour for Food; Chinese Light Industry Press: Beijing, China, 1993; pp. 123-145.

24. Kim, A.R.; Zou, Y.; Kim, H.S.; Choi, J.S.; Chang, G.Y.; Kim, Y.J.; Chung, H.Y. Selective peroxynitrite scavenging activity of 3-methyl-1,2-cyclopentanedione from coffee extract. J. Pharm. Pharmacol. 2002, 54, 1385-1392. [CrossRef] [PubMed]

25. Su, P.W.; Yang, C.H.; Yang, J.F.; Su, P.Y.; Chuang, L.Y. Antibacterial Activities and Antibacterial Mechanism of Polygonum cuspidatum Extracts against Nosocomial Drug-Resistant Pathogens. Molecules 2015, 20, 11119-11130. [CrossRef] [PubMed]

26. Yang, J.F.; Yang, C.H.; Wu, C.C.; Chuang, L.Y. Antioxidant and antimicrobial activities of the extracts from Sophora flavescens. J. Pharm. Phytochem. 2015, 3, 26-31.

Sample Availability: Samples of the wood vinegar are available from the Bu-Quang charcoal company (Kaohsiung, Taiwan).

(C) 2016 by the authors; licensee MDPI, Basel, Switzerland. This article is an open access article distributed under the terms and conditions of the Creative Commons Attribution (CC-BY) license (http://creativecommons.org/licenses/by/4.0/). 